Copyright

by

Matthew Ryan Chester

2016 
The Report Committee for Matthew Ryan Chester Certifies that this is the approved version of the following report:

\section{Gay Men's Experiences Coming Out Online: A Qualitative Study}

\section{APPROVED BY \\ SUPERVISING COMMITTEE:}

Supervisor:

Aaron Rochlen

Diane Schallert 
Gay Men's Experiences Coming Out Online: A Qualitative Study

by

Matthew Ryan Chester, B.A.

\author{
Report \\ Presented to the Faculty of the Graduate School of \\ The University of Texas at Austin \\ in Partial Fulfillment \\ of the Requirements \\ for the Degree of
}

Master of Arts

The University of Texas at Austin

May 2016 


\section{Dedication}

To my parents, John and Gail. Thank you for your unwavering support, patience, and humor. 


\begin{abstract}
Gay Men's Experiences Coming Out Online: A Qualitative Study
\end{abstract}

\author{
Matthew Ryan Chester, M.A. \\ The University of Texas at Austin, 2016
}

Supervisor: Aaron Rochlen

The current study employed qualitative methodology to investigate the experiences of 12 men who came out online, using Facebook. Analysis of coding data yielded several key themes. First, gay men discussed a range of experiences that influenced their online disclosure including homophobia, internalized homophobia, and previous salient sexual identity disclosures. Participants also commonly expressed a variety of goals and concerns about coming out online, including improving relationships and loss of friends. Finally, gay men identified several benefits to coming out on Facebook, including increased efficiency in coming out as compared to face-to-face disclosures, increased authenticity, and decreased ambiguity about their sexuality. Results are discussed within the context of literature on men's coming-out experiences, men and masculinity and online identity management. 


\section{Table of Contents}

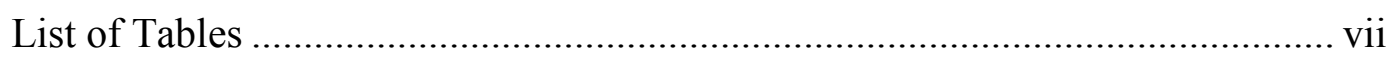

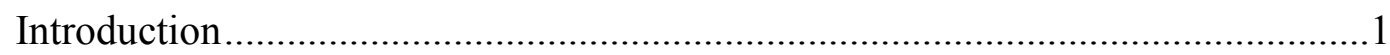

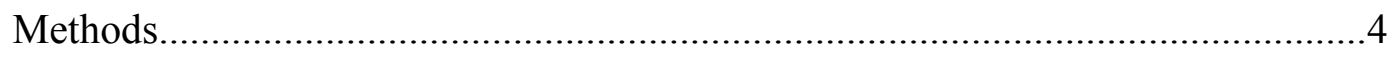

Participants and Procedures …………....................................................

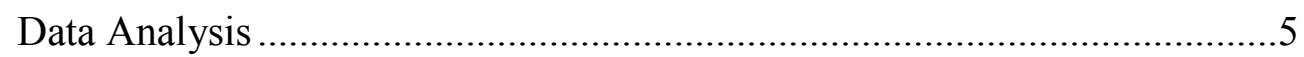

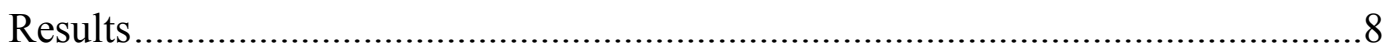

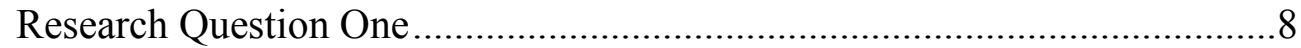

Experiences of Homophobia..............................................................

Internalized Homophobia....................................................................

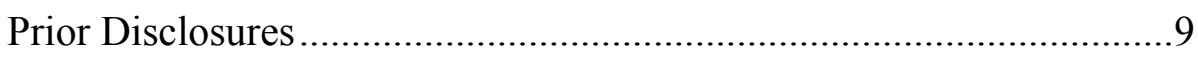

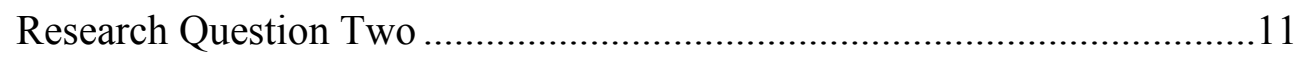

Anticipated Concerns .........................................................................11

Stated Goals and Outcomes ...............................................................12

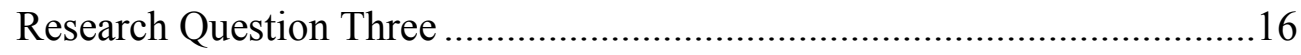

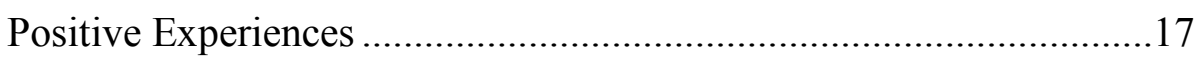

Negative Experiences...................................................................18

Neutral / Ambiguous Experiences ……………………………….....19

Emotional Context ………………………………………............19

Research Question Four .......................................................................22

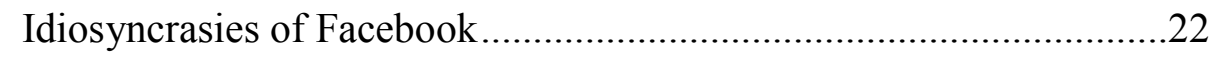

Coming-Out Method Comparisons......................................................23

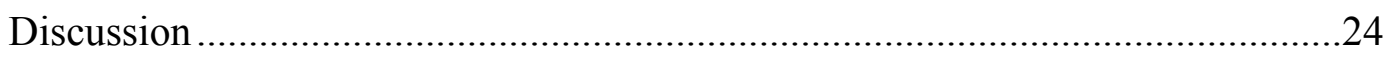

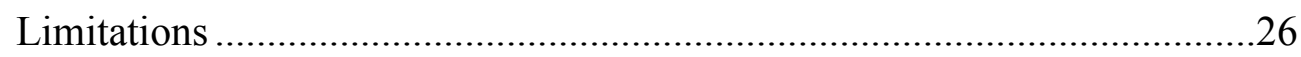

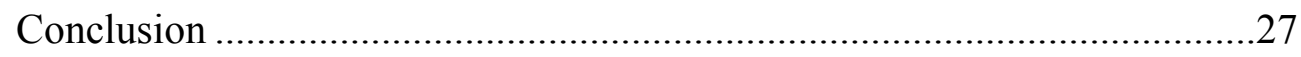

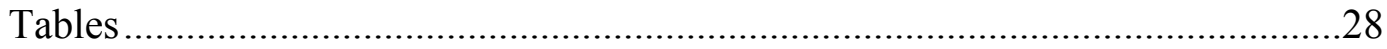

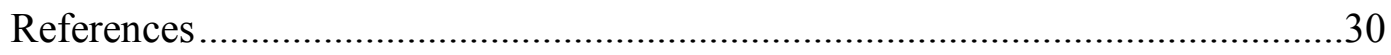




\section{List of Tables}

Table 1: Profile of Study Participants .............................................................28

Table n: Categories, Descriptions, and Percentages by Research Question .......29 


\section{Introduction}

The decision to either conceal or disclose one's sexual identity is a source of significant stress for gay individuals (DiPlacido, 1998; Meyer, 2003). Overall, concealment of one's sexual identity is associated with a range of negative outcomes including suicidality (Morris, Waldo, \& Rothblum, 2001), fewer job promotions (Ragins, Singh, \& Cornwell, 2007), lower satisfaction in same-sex relationships (Mohr \& Fassinger, 2006), incidence of cancer, and progression of HIV infections (Cole, Kemeny, Taylor \& Visscher, 1996). Conversely, research reports a positive association between sexual identity disclosures and mental health outcomes (e.g., Beals, Peplau, \& Gable, 2009; Bybee, Sullivan, Zielonka, \& Moes, 2009). Examples include diminished stress of secrecy (Rosario, Hunter, Maguen, Gwadz, \& Smith, 2001), increased self-esteem (Corrigan \& Matthews, 2003), and less internalized homophobia (Frost \& Meyer, 2009).

The risks associated with coming out may be especially pronounced for gay men. Evidence suggests that gay men are more often the targets of sexual prejudice than lesbian women and bisexual men (Bogaert \& Hafer, 2009; Herek, 2009). In comparison to lesbian women, gay men are more likely to engender stronger negative affective reactions, be regarded as mentally ill, and be perceived as child molesters (Herek, 2002). Further, gay men experience more heterosexist violence, property crimes, threatened violence, and verbal abuse than bisexual men and lesbian women (Herek, 2009). It is possible that gay men experience more violence because straight men's antigay sentiments are most often directed at gay men (Balsam, Rothblum, \& Beauchaine, 2005; Bogaert \& Hafer, 2009).

Current coming-out literature suggests that gay men may use a variety of disclosure methods in order to manage their sexual identity. However, nearly all research about coming out only considers verbal methods of direct disclosure (e.g., Orne, 2011; Savin- 
Williams, 2001). Given the paucity of research on coming out via non-traditional disclosure methods, our study aimed to provide a context for understanding this particular concept in greater depth. In particular, coming out on Facebook is an emerging topic of empirical interest.

Research suggests that coming out on Facebook is becoming more common. For example, Etengoff and Daiute (2014) found that 7 out of 15 gay Facebook users used the website as a tool to come out. Another study (Anderson, 2011) found that gay college athletes utilized Facebook as a means to disclose their sexual identity. While these studies support the growing prevalence of coming out on Facebook, no current studies have examined this method of disclosure in more depth.

Given the changing landscape of online social networking, it is important to expand our knowledge of coming out to this broader social context. Given the paucity of research on coming out via non-traditional disclosure methods, our study aimed to provide a context for understanding this particular concept in greater depth. Our study addressed gay men's use of Facebook as a means to disclose their sexual identity. Broad goals were to formulate a better understanding of gay men's decisions to come out online, identify concerns and goals for coming out online, and investigate differences between disclosure methods.

More specifically, we outlined four broad research questions aimed at providing core, descriptive data about gay men's coming out on Facebook. First, we asked gay men to describe their experiences of coming out prior to doing so on Facebook. This effort was led by our interest in better understanding men's history in this domain and gaining insight on how previous coming-out experiences might inform men's decisions to come out online. We were particularly interested in knowing to whom participants came out before their Facebook disclosures. Second, we were interested in the processes and outcomes of coming out via social media including men's concerns about disclosure, as well as what 
factors motivated gay men to come out on Facebook. Third, we aimed to better understand how gay men describe their experiences of coming out online including others' reactions, as well as costs of coming out on Facebook. Our final research question centered on the differences between coming out online versus other methods of disclosure. 


\section{Methods}

\section{Participants ANd Procedures}

Criteria for study participation included: a) identify as gay; b) 18 years of age or older; and c) used Facebook as a primary means for disclosing sexual orientation within the past five years. The definition of primary means of disclosure included any disclosure that was communicated via Facebook status update or post, and reached a significant number of a participant's contacts. All participants were recruited through snowball sampling, beginning with the principal investigator's (PI) personal social networks. Snowball sampling is effective for recruiting hard-to-access populations, such as sexual minorities (Bhutta, 2012; Browne, 2003). First, the PI disseminated an announcement about the present study on his personal profile. This announcement included a brief description of the study, the PI's institutional affiliation, and relevant Institutional Review Board information. Consequently, multiple individuals within the PI's social network shared the announcement on their Facebook pages.

Interviews were conducted and recorded via phone or video chat with each interview lasting between 40 and 90 minutes. The final pool of participants included 12 men, primarily Caucasian with an average age of 24.4. Hill, Thompson and Williams (1997) recommend to recruit between eight and 15 participants for qualitative studies. The majority of participants identified as Caucasian, were between 20 and 30 years old, and had a college degree. Descriptive information on each respondent can be found in Table 1.

Participants categorized their Facebook usage as rare, moderate, or active. Participants also reported a range of salient coming-out experiences prior to coming out on Facebook. A majority of participants $(n=10)$ indicated that they disclosed their sexual identity to their parents prior to coming out on Facebook through a variety of means 
including e-mail, letter, mass text message, telephone call, and in-person conversation. Participants also provided an estimate of how many individuals knew about their sexual identity prior to their Facebook disclosure. Estimates can be found under the subheading People Aware of Identity in Table 1.

Given the importance of researcher identity and bias in conducting qualitative research (Hill et al., 2005), we assembled a research team that could provide a variety of perspectives on gay men's coming-out experiences. Our final team was composed of six researchers: two straight white males (one professor and one doctoral student), two gay white male doctoral students, one bisexual female multiracial doctoral student, and one bisexual white female masters student.

Based on our research questions, we developed a semi-structured interview protocol comprised of 23 open-ended questions. The questions were designed to allow each participant to reflect openly on his subjective experience. An interviewer tested the protocol with one pilot interviewee who met study criteria. This pilot subject provided feedback about his interview, which led to minor revisions of interview questions. Because of the limited nature of these revisions, we included data from the pilot interview in our final data analysis. Interviews were conducted over a 2-month period.

\section{Data Analysis}

The research team developed an initial coding framework after interviews were transcribed. Our process followed the general guidelines of Consensual Qualitative Research (CQR; Hill et al., 1997, 2005), which delineates a team-based approach to data interpretation. Instead of coding separately and calculating inter-rater reliability, team members using CQR collaborate to assign final codes. Disagreements about coding were 
negotiated until consensus was reached. During this process, researchers carefully considered their own biases when making coding decisions.

CQR prescribes three steps for data analysis (Hill et al., 1997, 2005). First, we selected three transcripts at random and then identified and labeled domains of interest within each transcript. It is important to note that the domains stemmed from our initial research questions. For example, one domain was "stated goals and outcomes" (see Table 2 for examples).

Second, we identified core themes within each domain using all three transcripts. Core themes were derived from participant responses. An example of a specific core theme within the "stated goals and outcomes" domain was "inspire others to come out." Team members independently completed these steps before convening as a team to compare notes. Following our comparison, we developed a tentative list of codes that represented core themes that cohered between multiple participants. Independently, we applied this code list to one transcript to test its applicability within a new subsample. Third, we reconvened to collaboratively develop a final list of codes representing key thematic commonalities between participants. To be selected for final analysis, a code had to occur in at least 3 out of 12 transcripts, or $25 \%$ of participants.

Using the final code list, at least two team members separately read and coded each of the 12 transcripts, applying codes to applicable excerpts from each interview. Using a consensus process (Hill et al., 1997), the team members assigned a single set of final codes for each transcript. Next, a designated researcher entered all codes and excerpts into qualitative software, Dedoose, which facilitated organization and analysis of the data. Using Dedoose, this researcher compiled excerpts from all transcripts, organized by code category. A team member involved in the initial coding process audited this document to ensure validity. 
Following an initial audit, the auditor requested team members reconvene to revise the specificity of code names and organization of the coding framework. Team members met without the auditor to discuss and negotiate disagreements about the coding framework until consensus was reached. Next, a designated researcher used Dedoose to restructure the coding framework and compiled a document containing excerpts across all 12 transcripts, organized by code category. In the final step, the auditor reviewed this document, met with the team to resolve discrepancies, and verified the final data set. 


\section{Results}

Research questions, relevant themes and subthemes, and frequency of responses are outlined in Table 2. Below, descriptive results are organized by research question. Within each theme, we have selected representative quotes.

\section{RESEARCH QUESTION ONE: HOW DO PARTICIPANTS DESCRIBE THEIR PROCESS AND TIMING OF COMING OUT PRIOR TO FACEBOOK?}

\section{Experiences of Homophobia}

A majority of participants, 11 out of 12 , indicated that they had experienced homophobia from others. Four discussed receiving homophobic messages from family members, mostly parents. Seven recalled being the target of homophobia from their peers. One respondent shared a discussion he had with a college friend:

I don't know how the topic came up of gay people, but he just had this very intense look in his eye, and he said, "All gay people are sick in the head, and they deserve to be lined up and shot."

Four participants recalled experiencing homophobia within a religious context, specifically growing up in a Christian denomination, and learning that homosexuality was "wrong" or "a sin." Conversely, two men discussed receiving support from their Christian communities. One man noted that his religious friends were "incredibly supportive."

\section{Internalized Homophobia}

Five participants noted feelings of internalized homophobia, mainly described as shame about being identified as gay. Two discussed wanting to change, or "get rid of," their gay identity. Many described shame in the context of other's perceptions. One respondent stated: "I was just really worried about other people's perceptions. The worst thing that I could be called was gay. So I did everything in my power to not be perceived as gay." 


\section{Prior Disclosures}

Overall, the experience of coming out prior to social media was described in complex means. In analyzing data about prior experiences of coming out, we found that participants described these experiences differently depending upon the context in which their disclosure was communicated and to whom. Below, participants' various comingout experiences are described in detail based on common contexts that emerged from the data.

\section{Family}

A majority of participants, 11 out of 12 , indicated that they came out to at least one immediate family member prior to their Facebook disclosure. Ten and six reported coming out to parents and siblings, respectively. Participants employed a variety of disclosure methods when coming out to parents. Six men utilized direct verbal disclosure (e.g., "I'm gay”), mostly in person. Two sent a letter or e-mail, one sent a mass text message to his immediate and extended family, and one sent a letter to his father but came out to his mother in person.

Two men indicated that they did not come out to parents prior to coming out on Facebook. One participant noted, 'I haven't told them explicitly... Hey, 'I'm gay.' It's just one of those elephants in the room that you don't talk about." In contrast, another respondent indicated his parents discovered his sexual identity after examining his sister's Facebook feed.

Participants discussed a complex range of reactions from family members. One participant described his dad as "very supportive," while another outlined difficulty with his father: "He just couldn't accept it. That's the first time I really felt rejection from my father." One man divulged coming out to his mother was "a lot more difficult than I wanted," while another indicated his mother was "extremely supportive." Often, 
participants noted "varying degrees of acceptance or comfort or understanding" based on the family member. For instance, one man disclosed that coming out to his mother "was not as big of a deal," but his father said, "I disagree with [homosexuality]." In all cases, participants reported sibling reactions as positive.

\section{Friends}

Notably, eleven participants indicated that they told at least one friend about their sexual identity prior to their Facebook disclosure. One participant explained that the only individuals aware of his sexual identity were the men with whom he had romantic or sexual relationships.

Participants varied in their reasons for coming out to friends. Three mentioned others speculating, or "asking questions," about their sexual identity as a primary motivation to come out. Some described these experiences as "burdensome" and reported feeling "emotionally exhausted and drained" as a result. One man illustrated this experience:

To know that I'm going to have to sit down and talk to friends or acquaintances, or even people I just randomly met, and have a twenty-minute conversation about how great it is that I am gay... having the same conversation every day was really annoying.

In contrast, several participants viewed disclosing to close friends as a "stepping stone" to coming out in other contexts. One respondent admitted his concern of "[giving] off bad first impressions because I'm not out to everyone in my life." He noted that the decision to not disclose his sexual identity "affects the way I interact with people." Another man described the process and benefits of coming out to friends:

It was a slow weight off my shoulder. I felt like I was more connected with that person then, and they knew. You know, it's kind of your deepest darkest hidden secret, so you feel like you can be yourself with them. And that was important to form relationships, friendships. 
RESEARCH QUESTION TWO: WHAT ARE THE PROCESSES AND OUTCOMES OF GAY MEN'S DECISIONS TO COME OUT VIA SOCIAL MEDIA?

\section{Anticipated Concerns}

All 12 participants noted anticipated concerns from the disclosure. Concerns were commonly related to others' reactions. Specific concerns addressed by three or more men are noted below.

\section{General Disapproval}

A majority of participants, 7 out of 12, indicated they were concerned about general disapproval as a result of their disclosure. One participant anticipated that others would tell him "the gay lifestyle is wrong," while another worried his friends would be "against it." Two men invoked religious language, and stated that they expected messages "condemning me to hell" and to "fight the temptations." Further, one man described his concerns about disapproval, as well as his capacity to tolerate negative responses:

People would go with their kneejerk emotional response, which I suspect was a degree of disgust and $100 \%$ shock, or dismay, or disappointment, and I just didn't want that. I couldn't handle it.

\section{Lose Friends}

Half of participants indicated concerns about losing friends. One man commented, "I often questioned, 'How many friends am I going to lose?" Another man stated he was afraid to "lose those friendships," referring to closeted men with whom he was sexually involved. One participant explained his concerns about the consequences of disclosure. He commented, "These people could stop talking to me when I come out. They've been incredibly close to me and they love me as a person, but will they love me as a gay man?" 


\section{Hurt Others}

A majority of participants, 7 out of 12 , stated that they had concerns about their disclosure hurting others. For example, one man indicated concern about his ex-girlfriend "being harassed" because of his disclosure. Six reported concerns about hurting family members. Of these, one participant stated that he did not want family members "to answer questions about my lifestyle," and another indicated it would "devastate" his parents if they discovered his sexual identity on Facebook. Another man echoed sentiments of several participants: "I didn't want a bunch of people reaching out to my mom in this difficult time. That just irritated me. I didn't want her to have to reason or explain or justify."

\section{Question Facebook Disclosure}

Five participants noted a general concern that others would question their decision to come out on Facebook. One participant stated that he was concerned that "someone would have said, 'Why is this Facebook worthy? Why do you need to share this with the world? Maybe this is something that is private." Another participant worried that others might think, "'Why is he posting that on Facebook?"”

\section{Stated Goals and Outcomes}

All 12 participants noted at least one goal and outcome of coming out on Facebook. Specific goals and outcomes ranged from the concrete (e.g., clarification of one's sexuality) to the abstract (e.g., change others' attitudes about sexuality).

\section{Authenticity / Honesty}

A majority of participants, 10 out of 12 , identified authenticity or honesty as an aspect of their goals and outcomes. Participants described their disclosure as a way to share their "whole self" with others. One participant stated, "I felt like if I did not include [my sexual identity] in my online image that it... it was me not following through on who I 
was." Another man realized, "The thing that was the root of all these problems was the fact that I wasn't living genuinely." Many men indicated a desire to be more honest with themselves and others, and discussed fatigue related to hiding their sexuality:

I was tired of hiding who I was, not being able to express when I felt someone was attractive; I remember years that I would change "him" to "her" when I would speak of other people that I was attracted to. And I vividly remember just staring at myself in the bathroom mirror and saying, "I'm tired of lying to everyone else and myself."

In nearly all cases, participants discussed the difficulties associated with "pretending" or "lying" about their sexual identity. One man stated, "I just could not live the lie anymore," while another admitted, "I could not maintain the façade." Generally, respondents viewed Facebook as a way to promote honesty and authenticity: "I would be much more apt to discuss being gay or try to help someone else now because of Facebook," one participant stated. "If not for Facebook, I would still be closeted."

\section{Clarification}

Five participants explicitly stated a desire to resolve ambiguity about their sexuality. One participant noted, "I was primarily doing clarification," while another said, "I just wanted to clear the air." Other participants echoed these sentiments, noting that they wanted to "confirm people's suspicions" about their sexuality.

\section{Efficiency}

A majority of participants, 7 out of 12, discussed Facebook as a means of efficiently coming out to others. In all seven cases, participants specifically mentioned wanting to limit in-person discussions about their sexuality. Several men likened the process of coming out online to "removing a Band-Aid." Generally, participants described coming out on Facebook as a "very clean" and "succinct" way to "knock it all out at once." The following man's experience represents this general theme: 
Best-case scenario was limiting the number of times I would have to explain that I am gay, having to go through that whole routine so many times. I was just trying to get it out there so I didn't have to talk about it so much. Which ended up happening.

\section{Express Political Beliefs}

Three respondents reported that expressing political beliefs was an important facet of their online disclosure. One participant hoped to engage political discussions about "correcting societal norms" and "homophobia issues or body image" via his coming-out post. Another respondent echoed these sentiments and stated, "I wanted to be open about the politics I was discovering. I was finding myself to be a liberal and a feminist and someone who supported gay rights." Similarly, another man remarked that disclosing his sexual identity on Facebook enabled him to "get involved in equality debates [about] various things like racism, or sexism, or homophobia."

\section{Change Attitudes About Sexuality}

Half of participants endorsed changing others' attitudes about sexuality as either a goal or outcome. As one participant explained, "It was like, 'I am gay. I care about what you think so far as it affects the people around me, and I want to change people's minds about LGBT folks." Another participant discussed his goal of providing a positive portrayal of gay identity and demonstrating to his Christian friends that gay individuals "can live a happy, social, productive life." Similarly, one respondent discussed wanting to provide a positive example and "some level of comfort" to individuals "struggling with the issue of identity." Following their disclosure, some participants perceived changes in others' conceptions of sexuality. The following man's experience represents these perceived changes:

If not for Facebook, my father would still have that same old stereotypical view that he had before of gay people. Now my dad knows that I'm just a regular person. 
I'm no different than anyone else. Facebook allows him to see I'm still a good person and I still have a good life.

\section{Permanency}

Five participants discussed the importance of permanency in disclosing their sexual identity on Facebook. One participant stated, "It felt like a bridge I couldn't cross back over. It was a point of no return." Another participant echoed these comments, stating, "I wanted it to be permanent." In all five cases, participants stressed the idea of "no going back."

\section{Openness About Sexuality / Attractions}

A majority of participants, 7 out of 12, reported being more open about their sexuality and attractions following their disclosure. Some discussed their newfound willingness to post pictures with their romantic partners online. One indicated that he no longer holds back from sharing posts that implicate him as gay. He stated, "I am not policing my profile as much...trying to make it seem like I am this straight guy."

Interestingly, men's openness generalized beyond the digital realm into everyday contexts. One described no longer weighing decisions about how to come out to friends. He stated that disclosing on Facebook "meant that I could be public with it, as opposed to trying to decide if and when I could come out, or how to do it." Several noted that they were more willing to discuss their attractions. "I'm fine discussing my romantic experiences because now I know that it's okay." Overall, men described feeling more comfortable sharing aspects of themselves that they had previously "censored." The following man's experience succinctly represents this general theme: "I felt like I could interact more openly with people...I was less concerned with having people suspect I was gay [and] with behaving in a particular way." 


\section{Improved Relationships}

Half of participants reported that coming out online improved their relationships. One participant stated coming out "opened up connections I could have with people." Three participants specifically mentioned relationships with other sexual minorities. One stated, "I think for some people, it improved the relationship I had with them... I would say, especially with other people who identify as LGBTQ.” Another respondent compared his amount of social engagement before and after coming out on Facebook. He reflected:

Before then, I wasn't very social and didn't have very many friends. I kept people at a distance and now, I am double booked on the weekends and I have stuff happening all the time during the week. It's crazy unbelievable how much my life has changed.

\section{Inspire Others to Come Out}

Four participants noted that their disclosure inspired others to come out. One participant described this as a "domino effect," in which "two dozen guys came out to me." Another man described an ensuing "bandwagon" of individuals coming out online. One respondent articulated this phenomenon. He reflected:

There were even some people who used that [referring to own coming-out post] as an opportunity to kind of start coming out. I remember one girl telling me that she found it really compelling because she was struggling...that was the most exciting response that I got.

\section{RESEARCH QUESTION THREE: HOW DO GAY MEN DESCRIBE THEIR COMING OUT ON SOCIAL MEDIA?}

Participants' descriptions of coming out on social media tended to pertain to others' responses to their disclosure as well as their own internal emotional experiences. For the purposes of this analysis, descriptions of others' responses were organized by means of positive, negative, and neutral according to participants' self-reports. Emotional experiences were also organized according to participants' self-reported emotions. 


\section{Positive Experiences}

All 12 participants described receiving positive feedback and supportive comments after their disclosure. Many were struck by the warmth and magnitude of support they received. One man commented, "I put it online, and then out of nowhere all these people are showering me with adoration." Interestingly, eight participants indicated receiving only positive feedback. For example, one participant stated, "It was all 100\% positive," while another noted, "Any response I got was a positive response.” Five respondents mentioned others communicating feelings of pride. For example, one man stated, "I got a lot of "proud of you' and 'I am so happy' comments." In discussing the magnitude of support he received, one respondent echoed the sentiments of several participants. He stated, "I was definitely touched - it meant a lot to me."

Six participants discussed responses to their disclosure that occurred outside of Facebook. Many indicated that they received text messages from friends or colleagues expressing support and pride. Another man described in-person support from friends in his sports league:

I've become really close with a lot of the guys in the league. Many came up to me and let me know how inspirational my post was. They let me know that they loved me and supported me.

Eight participants indicated that at least one family member contacted them to express support following their online disclosure. Several respondents reported receiving "loving" text messages and voicemails from extended family members. One participant recalled: "My mom called me up and said she was so proud of me." Similarly, another participant indicated that his mother called him to say, "I'm proud of you doing what you needed to do to be happy." One man indicated that his father left a supportive Facebook comment. However, most participants indicated that their parents are not Facebook users. 


\section{Negative Experiences}

Overall, four participants indicated that they experienced at least one negative reaction to their Facebook disclosure. Two reported receiving negative comments on their coming-out posts. "There were people that said some slanderous things," one participant stated, "I had a couple people tell me, 'You're a faggot,' and so they were blocked." Another stated an individual quoted "biblical teachings" on his coming-out post. In contrast, 10 participants explicitly stated that they experienced "no negative feedback" on their Facebook posts. One participant reflected, “There wasn't a single negative comment.”

Three respondents reported being "unfriended" by select individuals on Facebook following their disclosure. One man noted, "I had a few friends who said a lot of derogatory things to me and then immediately unfriended me or they blocked me." Another respondent recalled that one of his childhood friends "defriended me on Facebook."

Four participants reported negative offline reactions related to their Facebook disclosure. One participant described an experience with a close family friend: "I know of at least one person from my church days who, after I came out, decided she didn't want to be my friend anymore." Another respondent reported hearing from his cousins that his aunt "was wondering why I did this on Facebook, as if it was an embarrassment to the family." Another man, whose parents learned of his sexual identity on Facebook, noted his father's reaction:

That is the day my dad stopped speaking to me. My father did not speak to me for two years. He would not take my phone calls. He was embarrassed that his son was a gay man. He told me that it's something he would never forgive me for.

Seven participants stated that they believed there were no negative costs or consequences to coming out on Facebook. One respondent declared, "I can't really think 
of a bad thing that came from it." In fact, while discussing individuals who removed him as a friend on Facebook, one participant stated, "If there's someone since then who has removed me, it is not a cost." Similarly, another participant discussed costs in terms of his profession:

I don't think there's a cost professionally. I don't want to work for anyone who doesn't support the LGBTQ community anyway. I wouldn't want to work for those types of people. If you're not going to hire me because I am gay, then I don't want to work for you or with you.

\section{Neutral / Ambiguous Experiences}

In addition to negative and positive experiences, half described either neutral or ambiguous reactions. One man recalled, "Probably 10 or $15 \%$ of the responses were just neutral." Another jokingly referenced ambiguous reactions, "Friends saying, "Ah, I thought you were checking me out that one time."' Another participant received messages from previous sexual partners. He commented:

A few of the gentlemen that I had sexual encounters with that had identified themselves as straight, I received many personal messages on Facebook-not comments - that said, "Please don't out me. Please don't ever tell anyone. My wife will leave me."

Several participants also discussed the importance of non-response to their online disclosure. One man noted, "I know of two cousins I didn't hear back from and that was probably the nicest thing they could have done." Another stated, "The worst response I ever got was no response."

\section{Emotional Context}

All participants discussed a range of emotions that they experienced throughout the process of coming out on Facebook. Men reported experiencing several emotions before, 
while writing, and after their disclosure. Emotions included feelings of fear, excitement, affirmation, happiness, anger, and confidence.

\section{Fear}

Four participants specifically described feelings of fear or terror. In most cases, men experienced fear prior to their disclosure. One participant noted, "I was scared with what the repercussions would be." Other respondents stated that the thought of being unable to "rescind the confession... was terrifying," and that they were "freaked out."

\section{Excitement}

Three men identified feeling excited during the process of coming out online. One participant noted, "I was excited about the concepts of the responses I was going to get." Another man indicated feeling excitement as one of a variety of emotions. He reflected: "Once I had sent that, I felt this huge kind of, sense of relief, and like excitement, and this overwhelming joy. And that wasn't something I was really expecting."

\section{Relief}

A majority of participants, 10 out of 12 , endorsed relief as a primary emotion felt after coming out online. In all cases, participants described feeling "relieved," or "liberated." One participant described his feelings of relief as "a big weight being lifted off my shoulders." Another respondent described coming out online as "the final release of all the tension and feelings and depression." One man recalled feeling relief about receiving support from others:

It was such a relief. I teared up at multiple times when I would read through post after post saying how I was supported by so many people that I thought I would lose. Whether they were a closer friend or not, I did not realize how many people would back me up on it. 


\section{Affirmation}

Four participants described the experience of coming out online as "affirming" or "validating." One man specifically discussed reading online comments from his extended family. He noted, "It was definitely affirming when I read through my cousin's and aunt's posts specifically... that's when it really hit home for me." Another participant also described feeling affirmed and supported by the larger LGBTQ community.

\section{Happiness}

Seven participants specifically mentioned experiencing happiness following their disclosure. One participant noted he was "completely happy," while another stated, "I was really happy, in a really good space." Another man described a combination of emotions, including happiness: "I was upset—I was tearful—but happy at the same time." He added, "It was a lot of mixed emotions."

\section{Anger}

Three respondents endorsed anger as a salient emotion related to their online disclosure. One participant reflected on his motivations to come out online: "I was like, 'Am I doing this because I am angry or because I want to?"' Another participant stated,

"There was almost an anger-slash-frustration at the actual coming-out part." One man also discussed feeling anger after friends blocked him on Facebook.

\section{Confidence}

Five participants specifically mentioned feeling more confident after coming out. One participant stated that he was "feeling very confident and courageous" before, during, and after his disclosure. One man stated he felt "more comfortable" with his sexuality, while another indicated he believed he "could be more expressive" of his sexual identity. 
RESEARCH QUESTION FOUR: HOW DOES COMING OUT ON SOCIAL MEDIA DIFFER FROM OTHER METHODS OF DISCLOSURE?

\section{Idiosyncrasies of Facebook}

A majority of participants, 11 out of 12, commented on the uniqueness of Facebook as a means of discussing sexual identity. For instance, one respondent likened Facebook to an "autobiography," while another described it as a "public space to express support for the LGBT community." Participants discussed the makeup of their Facebook friends list in the context of coming out online. One man noted, "There was an ease to the Facebook post, too, because it was more like, 'You're acquaintances... your opinion doesn't really matter to me very much." Another stated that coming out on Facebook "made it easier to find gay friends online."

Some participants commented on the use of Facebook as a way to disclose information about salient personal identities. One reflected, "It can be a space to have meaningful dialogue. And, in a sense, reveal who you truly are." Similarly, another participant noted distinctions between types of information shared on Facebook: "On Facebook you see everything from someone's birthday to their favorite food or moviestupid, trivial information like that. At the same time, you get personal information like their orientation and their religious affiliation."

Further, participants noted the ability to selectively filter or delete comments on their coming-out posts. One commented, "If you don't like what someone is saying or you don't really agree with what they are doing, it's as easy as blocking them." Similarly, another man described how Facebook provided him safety in coming out:

If someone said something that offended me, you can erase the comment or you can block that person. When you say something on Facebook, it's like saying it in an auditorium full of people. If you put it on Facebook in public and you're going to demean someone, then you're not only demeaning that person; you're demeaning 
every other person on Facebook who can see that post. To me, that was a layer of safety.

\section{Coming-Out Method Comparisons}

A majority of respondents, 10 out of 12, specifically compared Facebook to other methods of disclosure. Several participants noted differences between coming out to individuals and coming out online. One participant discussed these differences:

When you have an individual conversation with someone, you can say, "I'm still the same person." You can have a one-on-one experience and say all those specific things. When you come out on Facebook and it's general, you don't have that same one-on-one private experience.

Another man reflected on how others' reactions differ by coming-out method:

I think others are more apt to try to force their own opinions on you when one-onone. Say a gay person's going home to their mom and dad to come out. Those parents would be much more apt to force their opinions and beliefs on that person. I think it levels the playing field when you do it on Facebook. Anyone who's going to say anything to you - they're not just saying it to you.

Ten participants specifically mentioned wanting to come out to family or close friends individually before coming out on Facebook. In particular, several respondents reported wanting to come out to their parents beforehand. One echoed the sentiments of many, stating, "I wanted to tell my parents so that they did not find out on Facebook, and I wanted to tell them in person." Another man reflected on his decision to come out to family and close friends prior to Facebook:

Coming out online was really helpful in handling the connections in my life with acquaintances, coworkers, or people I had met in high school. If I had come out online and hadn't talked to my sister about it, that would have been really bad. I think considering which relationships you need to take the extra care of sitting down and having a heartfelt conversation about is important.

In contrast, one respondent cautioned against coming out to family in person, describing these disclosures as "more emotional" and "traumatizing." 


\section{Discussion}

Our study aimed to better understand gay men's experiences of coming out prior to online disclosure, their concerns and goals for coming out on Facebook, experiences of others' reactions to their disclosure, and perceived differences between methods of disclosure.

Overall, we found that the majority of men in our sample made at least one significant disclosure prior to coming out online. Specifically, 10 out of 12 men had come out to their parents, and all but one participant had come out to close friends or extended family members. Nearly all participants reported homophobia from family, friends, or coworkers, especially after sexual identity disclosures. Not surprisingly, participants' experiences of homophobia corresponded in many ways to the experiences of gay men in other studies, including rejection, harassment, threats of physical harm, and verbal abuse (e.g., Herek, 2009).

Results fit with various core themes found in other coming-out literature. First, men in our study reported a wide range of concerns about coming out online that are similar to concerns of men who come out in person. Specifically, participants discussed concerns of general disapproval, hurting others, losing friendships, and others' questioning of their decision to disclose. These concerns mirror those of gay men who come out using declarative statements in person (i.e., negative reactions, judgment, stigmatization, or rejection; Legate et al., 2012).

Second, a majority of participants reported increased feelings of authenticity and honesty. The connection between sexual identity disclosure and feeling more authentic, or true to one's self, has received broad support in both theories of identity development (e.g., Cass, 1979; Troiden, 1989) and qualitative studies (e.g., Savin-Williams, 2001). Our 
findings also align with earlier work on general self-disclosure, which has shown that sharing personal information is associated with a sense of congruence between individuals' personal and social selves (Jourard, 1972). Further, as a result of coming out online, a majority $(n=10)$ of participants reported feeling relief or liberation, which is also consistent with previous research (Monroe, 2001).

Importantly, all respondents in our study received multiple positive and supportive responses to their online coming-out disclosures. These findings correspond to previous research indicating that those who come out to more people report higher levels of perceived social support (Savin-Williams, 2001; Stevens, 2004). Further, six or more participants indicated that their relationships improved, and that they felt more comfortable openly discussing their sexuality following their online identity disclosure. These findings are consistent with sexual minority research that shows gay individuals feel more comfortable discussing romantic attractions following coming-out disclosures (e.g., Monroe, 2001; Savin-Williams, 2001).

Scholars disagree about the link between the use of social media and general mental health outcomes. For instance, Moreno et al. (2011) found that disclosures of emotion on Facebook helped users improve intimacy with others and elicit social support. However, other social-media research has suggested the use of Facebook to be associated with negative mental health consequences, such as anxiety and loneliness (e.g., Caplan, 2007; Kross et al., 2013). The findings of the present study highlighted the positive social aspects of disclosing personal information with others online. For instance, participants reported a number of benefits to coming out online (e.g., increased authenticity), and generally described their experiences as positive and socially supportive. These findings contribute to a growing body of literature that suggests that gay men may experience social and mental health benefits as a result of their online experiences with others (Etengoff \& Daiute, 2014). 


\section{LIMITATIONS}

The present study's results provide one of the first multifaceted descriptions of gay men's sexual identity disclosures on Facebook. However, the results must be interpreted in context of the data collection limitations. First, one of the limitations of the present study lies within the use of snowball sampling. Because this study employed social networks of the PI, the sample was limited in its diversity. Given this recruitment method, our final sample does not accurately represent a true cross-section of gay male demographics.

Because this study employed use of snowball sampling, the final sample of men may have mirrored characteristics of the social network from which they were recruited (Browne, 2003). For example, 11 of 12 participants were white men in their 20s. Indeed, the PI identifies as a gay, white male in his 20s. However, the unintentional exclusion of gay men in their 30 s and 40s may also represent a larger social change in which contemporary sexual-minority men are coming out at younger ages than previous generations (Cianciotto \& Cahill, 2003). In future studies of online sexual identity disclosures, efforts should be made to recruit participants from a wider range of ethnic, cultural, and educational backgrounds.

Second, gay men's experiences only represent part of the story of coming out online. Our study does not include experiences from bisexual or questioning men. Because each of these populations is at an equal or even greater risk of adverse mental health outcomes (Lewis, 2009; Schrimshaw, Siegel, Downing, Jr., \& Parsons, 2013), it is recommended that future studies of online identity disclosure include people from these groups. Recruiting these populations may be difficult, as bisexual and questioning men are less likely to disclose, and more likely to conceal, their sexual identities (Schrimshaw et 
al., 2013). Future research should also solicit information from bisexual and lesbian women, transgender individuals, and other sexual and gender minorities.

A third limitation of the study is the lack of examination of different disclosure strategies within Facebook. That is, our study only examined men who made explicit declarative statements about their sexual identity via status update. Other individuals may use more indirect strategies, such as posting pictures with their same-sex partner, updating their relationship status, or indicating "Interested in: Men” (Anderson, 2011; Orne, 2011). There may be significant process differences between these methods and declarative identity statements. In choosing to examine only declarative statements, we ignored other potentially meaningful coming-out experiences. In the future, it may be fruitful to study different disclosure strategies.

\section{CONCLUSION}

Despite a number of significant limitations, the current study suggests several promising new directions for research related to coming-out practices. In particular, the "strategic outness" construct, currently in the preliminary stages of research, may provide a useful avenue for future scholarship in the fields of LGB psychology and the psychology of men and masculinity. Meanwhile, social-media scholars stand to gain new insights from continued exploration of identity management strategies on Facebook. 
Table 1:

Profile of Study Participants $(N=12)$

\begin{tabular}{llcclcc} 
Name* & Race/Ethnicity & Age & $\begin{array}{c}\text { Age of } \\
\text { Disclosure }^{+}\end{array}$ & Education Level & $\begin{array}{c}\text { Facebook } \\
\text { Usage }\end{array}$ & $\begin{array}{c}\text { People Aware } \\
\text { of Identity** }\end{array}$ \\
\hline Sean & African-American & 26 & 25 & Bachelor's & Highly Active & $31-40$ \\
Kaleb & White & 25 & 20 & Master's & Highly Active & $11-20$ \\
Austin & White & 23 & 22 & Bachelor's & Highly Active & $1-10$ \\
Billy & White & 27 & 24 & Bachelor's & Highly Active & $1-10$ \\
Enrique & Hispanic & 24 & 24 & Some Graduate School & Highly Active & $11-20$ \\
Tommy & White & 22 & 18 & Bachelor's & Highly Active & $101+$ \\
Zack & Multiracial & 21 & 21 & Some College & Highly Active & $21-30$ \\
Brandon & White & 31 & 27 & Associate's & Highly Active & $1-10$ \\
Chad & Hispanic & 23 & 21 & Some College & Highly Active & $1-10$ \\
Logan & White & 22 & 19 & Associate's & Highly Active & $51-100$ \\
Mike & White & 23 & 23 & Bachelor's & Moderate & $51-100$ \\
Jason & White & 26 & 25 & Bachelor's & Moderate & $1-10$ \\
Note. ${ }^{*}$ All names provided are pseudonyms. ${ }^{* *}$ Represents participants' best estimate of individuals aware of sexual identity prior to Facebook \\
disclosure ${ }^{+}$specific to Facebook disclosure
\end{tabular}


Table 2:

Categories, Descriptions, and Percentages by Research Question

\begin{tabular}{|c|c|}
\hline Category \& descriptions* & $\mathrm{n}^{* *}(\%)$ \\
\hline \multicolumn{2}{|c|}{$\begin{array}{l}\text { Q1: How do participants describe their process and timing of coming out prior to } \\
\text { Facebook? }\end{array}$} \\
\hline Experiences of homophobia & $11(91.7)$ \\
\hline Internalized homophobia & $5(41.7)$ \\
\hline \multicolumn{2}{|l|}{ Prior Disclosures } \\
\hline Family & $11(91.7)$ \\
\hline Friends & $12(100)$ \\
\hline \multicolumn{2}{|c|}{$\begin{array}{l}\text { Q2: What are the processes and outcomes of gay men's decisions to come out on } \\
\text { social media? }\end{array}$} \\
\hline \multicolumn{2}{|c|}{ Anticipated concerns } \\
\hline General disapproval & $7(58.3)$ \\
\hline Lose Friends & $6(50.0)$ \\
\hline Hurt Others & $7(58.3)$ \\
\hline Question Facebook Disclosure & $5(41.7)$ \\
\hline \multicolumn{2}{|l|}{ Stated goals and outcomes } \\
\hline Authenticity / honesty & $10(83.3)$ \\
\hline Clarification & $5(41.7)$ \\
\hline Efficiency & $7(58.3)$ \\
\hline Express political beliefs & $3(25.0)$ \\
\hline Change attitudes about sexuality & $6(50.0)$ \\
\hline Permanency & $5(41.7)$ \\
\hline Openness about sexuality / attractions & $7(58.3)$ \\
\hline Improved relationships & $6(50.0)$ \\
\hline Inspire others to come out & $4(33.3)$ \\
\hline \multicolumn{2}{|c|}{ Q3: How do gay men describe their experiences of coming out on social media? } \\
\hline Positive Experiences & $12(100)$ \\
\hline Negative Experiences & $4(33.3)$ \\
\hline Neutral / Ambiguous Experiences & $6(50.0)$ \\
\hline \multicolumn{2}{|l|}{ Emotional Context } \\
\hline Fear & $4(33.3)$ \\
\hline Excitement & $3(25.0)$ \\
\hline Relief & $10(83.3)$ \\
\hline Affirmation & $4(33.3)$ \\
\hline Happiness & $7(58.3)$ \\
\hline Anger & $3(25.0)$ \\
\hline Confidence & $5(41.7)$ \\
\hline \multicolumn{2}{|c|}{$\begin{array}{l}\text { Q4: How does coming out on social media differ from other methods of } \\
\text { disclosure? }\end{array}$} \\
\hline Idiosyncrasies of Facebook & $11(91.7)$ \\
\hline Coming-out method comparisons & $10(83.3)$ \\
\hline
\end{tabular}




\section{References}

Anderson, E. (2011). Updating the outcome: Gay athletes, straight teams, and coming out in educationally based sports teams. Gender \& Society, 25, 250-268.

Balsam, K. F., Rothblum, E. D., \& Beauchaine, T. P. (2005). Victimization over the life span: A comparison of lesbian, gay, bisexual, and heterosexual siblings. Journal of Consulting and Clinical Psychology, 73, 477-487.

Beals, K. P., Peplau, L. A., \& Gable, S. L. (2009). Stigma management and well-being: the role of perceived social support, emotional processing, and suppression. Personality and Social Psychology Bulletin, 35, 867-79.

Bhutta, C. B. (2012). Not by the book: Facebook as a sampling frame. Sociological Methods and Research, 41, 57-88.

Bogaert, A. F., \& Hafer, C. (2009). Predicting the timing of coming out in gay and bisexual men from world beliefs, physical attractiveness, and childhood gender identity/role. Journal of Applied Social Psychology, 39, 1991-2019.

Browne, K. (2003). Snowball sampling: Using social networks to research nonheterosexual women. International Journal of Social Research Methodology, 8, 47-60.

Bybee J. A., Sullivan E. L., Zielonka E., \& Moes E. (2009). Are gay men in worse mental health than heterosexual men? The role of age, shame and guilt, and coming-out. Journal of Adult Development, 16, 144-154.

Caplan, S. (2007). Relations among loneliness, social anxiety, and problematic Internet use. CyberPsychology \& Behavior, 10, 234-242. 
Cass, V. C. (1979). Homosexuality identity formation. Journal of Homosexuality, 4, 219235.

Cianciotto, J., \& Cahill, S. (2003). Education policy: Issues affecting lesbian, gay, bisexual, and transgender youth. New York, NY: National Gay and Lesbian Task Force Policy Institute.

Cole, S. W., Kemeny, M. E., Taylor, S. E. \& Visscher, B. R. (1996). Elevated physical health risk among gay men who conceal their homosexual identity. Journal of Health Psychology, 15, 243-251.

Corrigan, P. W. \& Matthews, A. K. (2003). Stigma and disclosure: Implications for coming out of the closet. Journal of Mental Health, 12, 235-248.

D'Augelli, A. R. (2006). Developmental and contextual factors and mental health among lesbian, gay, and bisexual youths. In A.E. Omoto \& H. M. Kurtzman (Eds.), Sexual orientation and mental health: Examining identity and development in lesbian, gay, and bisexual people (pp. 37-53). Washington DC: APA Books.

DiPlacido, J. (1998). Minority stress among lesbians, gay men and bisexuals: A consequence of heterosexism, homophobia, and stigmatization. In G. M. Herek (Ed.), Stigma and Sexual Orientation (p. 138-169). Thousand Oaks, CA: Sage.

Etengoff, E. \& Daiute, C. (2014). Online coming-out communications between gay men and their religious family allies: A family of choice and origin perspective. Journal of GLBT Family Studies, 1-27.

Fassinger, R. E. (1991). The hidden minority: Issues and challenges in working with lesbian women and gay men. The Counseling Psychologist, 19, 157-176. 
Frost, D. M., \& Meyer, I. H. (2009). Internalized homophobia and relationship quality among lesbians, gay men, and bisexuals. Journal of Counseling Psychology, 56, 97-109.

Herek, G. M. (2002). Heterosexuals attitudes toward bisexual men and women in the United States. Journal of Sex Research, 39, 264-274.

Herek, G. M. (2009). Hate crimes and stigma-related experiences among sexual minority adults in the United States: Prevalence estimates from a national probability sample. Journal of Interpersonal Violence, 54-74.

Hill, C. E., Knox, S., Thompson, B. J., Williams, E., Hess, S. A., \& Ladany, N. (2005). Consensual qualitative research: An update. Journal Of Counseling Psychology, 52(2), 196-205.

Hill, C. E., Thompson, B. J., \& Williams, E. N. (1997). A guide to conducting consensual qualitative research. The Counseling Psychologist, 25, 517-572.

Jourard, S. M. (1972). The transparent self (2nd ed.). New York: Van Nostrand.

Kross, E., Verduyen, P., Demiralp, E., Park, J., Lee, D. S., Lin, N., \& Ybarra, O. (2013). Facebook use predicts declines in subjective well-being in young adults. PLoS ONE, 8, 1-5.

Legate, N., Ryan, R. M., \& Weinstein, N. (2012). Is coming out always a "good thing”? Exploring the relations of autonomy support, outness, and wellness for lesbian, gay, and bisexual individuals. Social Psychological \& Personality Science, 3, $145-152$. 
Lewis, N. M. (2009). Mental health in sexual minorities: Recent indicators, trends, and their relationships to place in North America and Europe. Health \& Place, 15, $1029-1045$.

Meyer, I. H. (2003). Prejudice as stress: Conceptual and measurement problems. American Journal of Public Health, 93, 262-265.

Mohr, J. J., \& Fassinger, R. E. (2006). Sexual orientation identity and romantic relationship quality in same-sex couples. Personality and Social Psychology Bulletin, 8, 1085-1099.

Monroe, E. J. (2001). Drawing upon the experiences of those who are out: A qualitative study of coming-out process of gays and lesbians. Doctoral dissertation, The University of Iowa.

Moreno, M. A., Jelenchick, L. A., Egan, K. G., Cox, E., Young, H., Gannon, K. E. \& Becker, T. (2011). Feeling bad on Facebook: Depression disclosures by college students on a social networking site. Depression and Anxiety, 28, 447-455.

Morris, J. F., Waldo, C. R., \& Rothblum, E. D. (2001). A model of predictors and outcomes of outness among lesbian and bisexual women. American Journal of Orthopsychiatry, 71, 61-71.

Orne, J. O. (2011). 'You will always have to "out" yourself': Reconsidering coming out through strategic outness. Sexualities, 14, 681-703.

Ragins, B. R., Singh, R., \& Cornwell, J. M. (2007). Making the invisible visible: Fear and disclosure of sexual orientation at work. Journal of Applied Psychology, 92, 1103118. 
Rosario, M., Hunter, J., Maguen, S., Gwadz, M. \& Smith, R. (2001). The coming-out process and its adaptational and health-related associations among gay, lesbian, and bisexual youths: Stipulation and exploration of a model. American Journal of Community Psychology, 29, $113-160$.

Savin-Williams, R. C. (2001). Mom, dad. I'm gay: How families negotiate coming out. Washington D.C.: American Psychological Association.

Schrimshaw, E. W., Siegel, K., Downing, Jr., M. J., \& Parsons, J. T. (2013). Disclosure and concealment of sexual orientation and the mental health of non-gayidentified, behaviorally bisexual men. Journal of Consulting and Clinical Psychology, 81, 141-153.

Stevens, R. A. (2004). Understanding gay identity development within the college environment. Journal of College Student Development, 45, 185-206.

Troiden, R. R. (1989). The formation of homosexual identities. Journal of Homosexuality, 17, 43-73. 